熔鉄の窒素の溶解度におよばす炭素，珪素，マンガンの影響*

（熔鉄の窒素の溶解度について一I）

前川静 弥**. 中川義 隆**

\title{
Solubility of Nitrogen in Liquid Iron and Effect of Carbon, Silicon and Manganese on the Solubility.
}

\author{
(Solubility of nitrogen in liquid iron and iron alloys-I)
}

Shizuya Maekawa and Yoshitaka Nakagawa

Synopsis:

The solubilities of nitrogen in liquid iron and liquid $\mathrm{Fe}-\mathrm{C}, \mathrm{Fe}-\mathrm{Si}$ and $\mathrm{Fe}-\mathrm{Mn}$ alloys were measured at $1500 \sim 1700^{\circ} \mathrm{C}$.

The results on liquid iron confirmed that Sievert's law was followed in the range 95 to 760 $\mathrm{mmHg}$ pressure.

The results obtained were as follows:

(1) The solubility of nitrogen in liquid pure iron was expressed as follows:

$$
\% \underline{\mathrm{N}}=1.2 \times 10^{-5} \times \mathrm{T}+0.0171
$$

(2) The effect of carbon, silicon and manganese on the activity coefficient of nitrogen in liquid iron alloys was calculated by the following relation:

$\log f_{N}=\log \mathrm{C}^{0}{ }_{N}-\log \mathrm{C}_{N}$

(3) The effect of alloying elements on the activity coefficient of nitrogen in liquid iron was summarized as below:

$$
\begin{array}{ll}
\log f_{N}^{(\mathrm{C})}=+0 \cdot 135 . \% \mathrm{C} & \mathrm{C}<4 \% \\
\log f_{N}^{(\mathrm{SI})}=+0 \cdot 048 . \% \mathrm{Si} & \mathrm{Si}<4 \% \\
\log f_{N}^{(\mathrm{Mn})}=-0.020 \% \cdot \% \mathrm{Mn} & \mathrm{Mn}<4 \%
\end{array} \quad 1500 \sim 1700^{\circ} \mathrm{C}
$$

I. 緒 言

鋼の合金元素としての窒素注最近しだいに注目され て, 特にオーステナイト安定戍や高温強度の増加元素と して有用である.また，窒素はオーステナイト結晶粒度 に大きな影響をあたえ，さらには熔鋼中の窒素は㠜固に 際して気泡系の欠樎の原因となる可能性を有している.

このように窒素は鋼質に大きな影響を有するので精鍊 過程において，その含有量を低下，あるいは增加して調 整する必要が生ずる.しかしこのためには熔鋼中の窒素 の熔解度や活量俰数を正確に知る必要がある.

熔鉄の窒素の溶解度や活量係数については，与に多 くの研究報告も発表されているが必ずしも満足できる結 果を示していない. 本報告においては熔融純 $\mathrm{Fe}, \mathrm{Fe}-\mathrm{C}$ 系, $\mathrm{Fe}-\mathrm{Si}$ 系, $\mathrm{Fe}-\mathrm{Mn}$ 系熔融合金の空素溶解度を温度 1500〜 $1700^{\circ} \mathrm{C}$ にわたつて測定した結果を報告する.

\section{II. 実 験 の方 法}

\section{1. 要旨}

1/8〜1 気圧の窒素の下で純鉄， 1 気圧の窒素の下で $\mathrm{Fe}-\mathrm{C}$ 系, $\mathrm{Fe}-\mathrm{Si}$ 系, $\mathrm{Fe}-\mathrm{Mn}$ 系の合金を熔融し, 各種 の温度で窒素を熔融合金中に飽和するまで吸収溶解させ た.

この間，一定時間ごとに試料を採取し，これを化学分 析により窒素を定量して窒素吸収曲線を求め, これより 飽和溶解度を求めた。

2. 実験装置

実験の装置は窒素，水素およびアルゴンガスの洗浄装 置および合金熔融坩堝をおさめた反応管よりなつてい

* 昭和 34 年 4 月本会講演大会にて発表

** 株式会社日本製銅所室蘭製作所研究所, 理博 


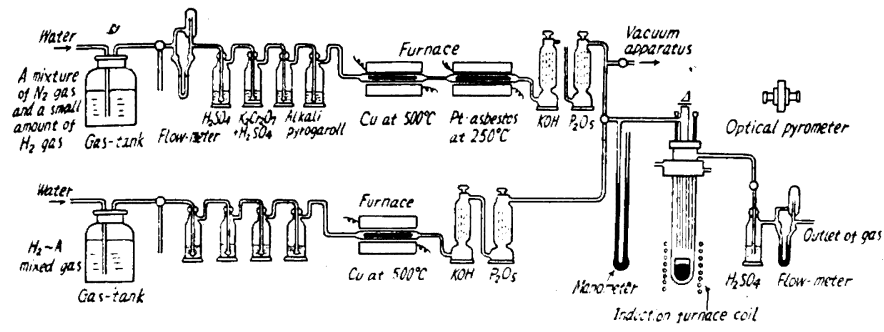

Fig. 1. Apparatus used in experiments. る. ガスの洗浄系列の細部は Fig. 1 に示すごとくであ り，特に窒素中の酸素除去を主眼とした．本系列を用い 実験と同じ条件で窒素ガスをとおし，その中の酸素量を 調べ実験には影響ないことを確認した.

反応管は Fig. 2 に示すごとく高アルミナ質坩塥によ つて保護した電融アルミナ質の合金熔融用坩堝（内径30 $\mathrm{mm}$ 高さ $50 \mathrm{~mm}$ )

を管中におさめ， この中の試料を高 周波炉（水銀ギャ ップ式 $10 \mathrm{kVA}$ ) で熔解するごとく した. 分析試料は 困に示すごとく， 二重すり合せ注射 管の内管のさきに 取付けた内径 3〜 $4 \mathrm{~mm}$ の不透明石 英製試料吸引管に よつて採取した。 その要領注，㩭汼 用石英管（試料吸 引管と同じょうに 別の注射管につけ

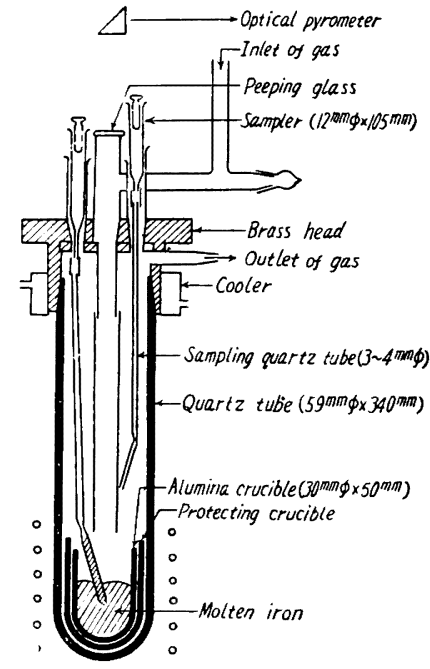

Fig. 2. Apparatus for melt of iron.
ておく)でよく㩭找した後，注射管内管を押し下げ石英 管の奖端を熔鉄中に入れて吸引した。

\section{3. 供試料}

実験に用いた純鉄は，真空熔解炉で $5 \mathrm{~kg}$ の電解鉄を 熔解し予備的に各種ガス成分を除去して小鋼塊とし，こ れを実験用坩堝に適合するよう成形したものを用いた. その化学組成はつぎのごとくである.

供試純鉄の化学組成

$\begin{array}{cccccc}\text { 成分 } & \mathrm{C} & \mathrm{Si} & \mathrm{Mn} & \mathrm{O} & \mathrm{N} \\ \% & <0.006 & <0.005 & <0.005 & <0.01 & <0.003\end{array}$

また各種添加金属の純度を次に示与。 添加金属の純度 金属名 $\mathrm{Si} \mathrm{Mn}$

$\% \quad 99 \quad 99$

また， $\mathrm{Fe}-\mathrm{C}$ 采合金の加炭剂として は，真空熔融法による酸素分析に用いる 純良な黑鉛坩㶡と前記電解鉄とによつて あらかじめ熔製したカーボン鉄を用い た。

4. 温度測定

溶解度測定時とまつたく同じ状態で，白金一白金口シ ウム熱電対（純ニッケルの熔融点で補正）と，光高温計 との同時測定を行なつて光高温計を補正し，実験中は光 高温計によつて温度測定を行なつた。実験中は所定実験 温度に対し $\pm 5^{\circ} \mathrm{C}$ であつた。

\section{5 . 実験順序}

試料約 $125 \mathrm{~g}$ を反応管内の坩堝におさ河，装置内を水 素一アルゴン混合ガス（1：1）にて完全に置換したるの ち, 高周波電気炉を作動して試料を熔解し，完全に熔解 後, 混合ガスを $100 \mathrm{cc} / \mathrm{mn}$ の割合で通じながら約 40 分 間 $1600^{\circ} \mathrm{C}$ に保持する. ついで反応管内を一旦真空とし たのち，窒素ガスに切換え $150 \mathrm{cc} / \mathrm{mn}$ の割合でとおし ながら所定温度に保持する，そののち，10２0分ごとに 分析試料を 2 $5 \mathrm{~g}$ ずつ採取する. 採取試料は直ちに水 冷して分析に供する.

6. 分析方法

試料の窒素分析は, アンモニア蒸溜一中和滴定法，ま た炭素，珪素およびマンガンの分析は学振鉄鋼迅速分析 法によつて行なつた.

7. その他

実験中熔融合金の中にアルミニウム，または珪素が坩 堝材より還元して混入するおそれがあるので，Fe-C 系 熔融合金の炭素量約 $3 \%$, 温度 $1700^{\circ} \mathrm{C}$ の場合について 実験後の合金中のアルミニウムと珪素を分析したが全然 増加していないので，混入はないものと考えた。また， 吸引儿た熔鉄試料の凝固過程において空素放出の有無が 問題となるので同時に吸引採取した 2 個の試料の一方を そのまま放冷させ，一方は水冷して凝固せしめた，その 両者の窒素分析值は Table 1 のごとくである.

この結果より, 凝固条件によつて窒素量はふなり変動 し, 自然放冷では，凝固過程に一部放出することがうか がわれた.したがつて本実験における試料は，採取後た だちに水冷凝固した. 
Table 1. Effect of conditions of solidification on nitrogen analysis.

\begin{tabular}{|c|c|c|c|c|c|c|c|c|c|}
\hline \multirow{2}{*}{$\begin{array}{l}\text { Exp. temp. } \\
{ }_{\mathrm{C}}\end{array}$} & \multicolumn{2}{|c|}{$\mathrm{N} \quad$ (p.p.m.) } & \multirow{2}{*}{\multicolumn{2}{|c|}{$\begin{array}{l}\text { Alloying } \\
\text { element } \\
\%\end{array}$}} & \multirow{2}{*}{$\begin{array}{c}\text { Exp. temp. } \\
{ }^{\circ} \mathrm{C}\end{array}$} & \multicolumn{2}{|c|}{$\mathbf{N} \quad$ (p.p.m.) } & \multirow{2}{*}{\multicolumn{2}{|c|}{$\begin{array}{c}\text { Alloying } \\
\text { element } \\
\%\end{array}$}} \\
\hline & $\begin{array}{l}\text { Cold in } \\
\text { water }\end{array}$ & $\begin{array}{l}\text { Cold in } \\
\text { still air }\end{array}$ & & & & $\begin{array}{l}\text { Cold in } \\
\text { water }\end{array}$ & $\begin{array}{l}\text { Cold in } \\
\text { still air }\end{array}$ & & \\
\hline $\begin{array}{l}1500 \\
1500 \\
1550 \\
1600 \\
1650 \\
1700 \\
1700 \\
1550\end{array}$ & $\begin{array}{l}304 \\
258 \\
246 \\
233 \\
253 \\
310 \\
250 \\
429\end{array}$ & $\begin{array}{l}303 \\
230 \\
219 \\
222 \\
155 \\
235 \\
194 \\
412\end{array}$ & $\begin{array}{l}\mathrm{C} ; \\
\mathrm{C} ; \\
\mathrm{C} ; \\
\mathrm{C} ; \\
\mathrm{C} ; \\
\mathrm{C} ; \\
\mathrm{C} ; \\
\mathrm{C} ;\end{array}$ & $\begin{array}{l}1 \cdot 18 \\
1 \cdot 73 \\
1 \cdot 76 \\
1 \cdot 63 \\
1 \cdot 49 \\
0 \cdot 67 \\
1 \cdot 29 \\
0 \cdot 52\end{array}$ & $\begin{array}{l}1550 \\
1550 \\
1600 \\
1600 \\
1650 \\
1650 \\
1700 \\
1550\end{array}$ & $\begin{array}{l}382 \\
367 \\
390 \\
349 \\
415 \\
411 \\
387 \\
436\end{array}$ & $\begin{array}{l}405 \\
395 \\
411 \\
336 \\
371 \\
363 \\
331 \\
441\end{array}$ & $\begin{array}{l}\mathrm{Si} ; \\
\mathrm{Si} ; \\
\mathrm{Si} ; \\
\mathrm{Si} ; \\
\mathrm{Si} ; \\
\mathrm{Si} ; \\
\mathrm{Si} ; \\
\mathrm{Mn} ;\end{array}$ & $\begin{array}{l}0.99 \\
2 \cdot 10 \\
1 \cdot 14 \\
1.92 \\
0.99 \\
1.93 \\
1.96 \\
0.24\end{array}$ \\
\hline
\end{tabular}

\section{III. 実 験 結 果}

1. 純熔鉄の窒素溶解度

純熔融鉄に窒素が吸収飽和量に到達する時間は, 窒素 圧，実験温度によつて多少異なり窒揫圧が大で実験温度 の高い場合で 100 分程度, 圧が小で温度の低い場合は, 140 分程度くある. Fig. 3 に窒素圧 1 気圧の場合の各 温度に抢ける飽和溶解度をほかの 2,3 の研究結果とと もに示した。

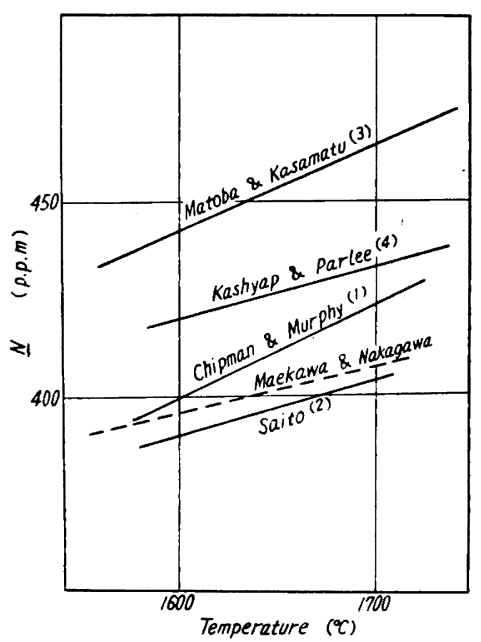

Fig. 3. Effect of temperature on the solubility of nitrogen in iron at $760 \mathrm{mmHg}$ gas pressure.

すなわち筆者らの測定値は CHIPMAN \& MURPHY ${ }^{1)}$ 斉藤2つらとのほほ中間の值を示している.この測定値よ り

$$
\% N=1.2 \times 10^{-3} \cdot T+0.071
$$

（たたし \% は は窒素飽和吸収量，Tは絶対温度） また，空素分圧と空素飽和吸収量との関係は Fig. 4 に 示すごとくで両者は明らかに SIEVERT の法則にしたが
つている.

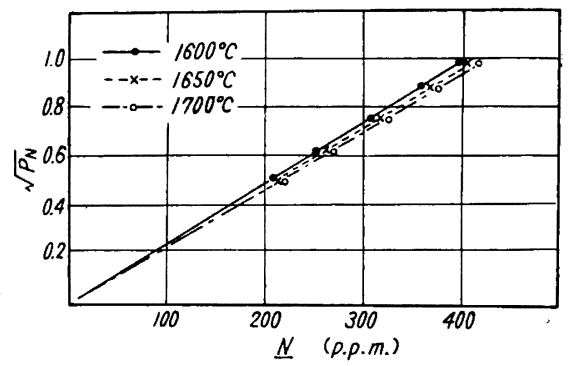

Fig. 4. Effect of pressure on the solubility of nitrogen in iron.

純熔鉄中への $N$ の溶解は

$1 / 2 N_{2}=\underline{N}$

$K=\% \underline{N} \cdot f_{N} / \sqrt{P_{N}}$

(ここでKは（1）式の平衡恒数， $N$ は熔鉄中の窒素量 $f_{N}$ は $N$ 自体が $N$ の活量におよほす活量係数, $P_{N}$ は $N_{2}$ の分圧)

しかし，この場合 Sievert の法則にしたがうから $f_{N}$ $=1$ と見做してもよい. よつて $\log K$ と $T$ との関釈 を求めると，

$$
\left.\begin{array}{l}
\log K=-500 / T-1 \cdot 136 \\
\Delta F^{\circ}=2288+5 \cdot 20 T
\end{array}\right\}(2)
$$

が得られる.

2. $\mathrm{Fe}-\mathrm{C}, \mathrm{Fe}-\mathrm{Si}$ および $\mathrm{Fe}-\mathrm{Mn}$ 系熔融合金の窒素 溶解度

1） $\mathrm{Fe}-\mathrm{C}$ 系: 本系の熔融合金に抒いては $1550^{\circ} \mathrm{C}$ 以下の場合約 40 分, $1600^{\circ} \mathrm{C}$ 以上では約 20 分で完全 に飽和量に達している. 窒素の溶解度と炭素量との関係 を Fig. 5 に示したが, 炭素量の増加とともに溶解度は いちじるしく隇少している.

口） $\mathrm{Fe}-\mathrm{Si}$ 系：本系の熔融合金は, $1550 \sim 1700^{\circ} \mathrm{C}$ の温度範囲では䄪 25 分で完全に飽和量に達している. 窒素の溶解度と珪秦量との関係は Fig. 5 のごとくであ 
るが，Fe-C 系の場合と同じように珪素量の增加ととも 《溶解度は減少している. しかしその程度は炭素の場合 より小さい.

CHIPMANら (佐野ら $^{6}$ によると珪秦約 $2 \%$ までは窒 素の溶解度は増加しそれ以下では減少なることを報告し ている. また, 斉藤ら2) も微量珪素の存在によつて窒素 の溶解度がいちじるしく増加すると述べている.しかる に本実験結果では珪素の存在に比例して窒素の溶解度は 明らかに減少している。これは実験方法の相違などによ ると考えられ今後さらに検討を要する.

八) $\mathrm{Fe}-\mathrm{Mn}$ 系: 本系の熔融合金は $1550 \sim 1700^{\circ} \mathrm{C}$ の温度範囲では 20 分間で完全に飽和量に達している. 窒素の溶解度とマンガン量との関係は Fig: 5 のごとく であり, マンガン量の増加とともに溶解度は, わずかに 堌加している。

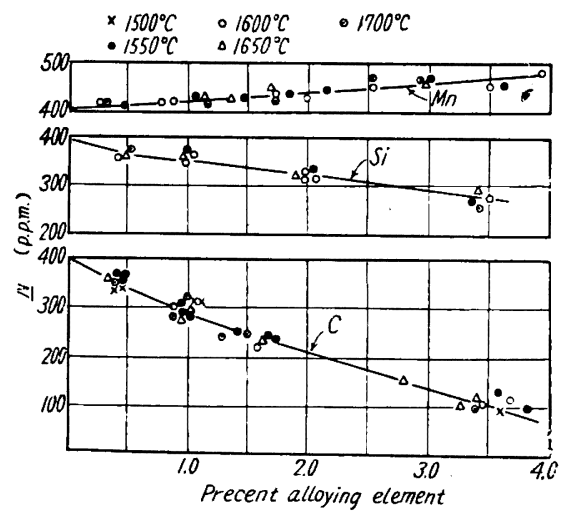

Fig. 5. Solubility of nitrogen in liquid iron alloys.

\section{IV. 実験結果の考察}

1. 窒素の活量係数におよほす炭素, 珪素およびマン ガンの影隦

今, 第 3 成分 $\mathrm{M}$ の存在する $\mathrm{Fe}-\mathrm{N}-\mathrm{M}$ 系熔融合金中の 窒素の活量におよほす 係数を $f_{N}^{(M)}$ とすると

$$
\log f_{N}^{(M)}=\log C_{N}^{0}-\log C_{N}^{M}
$$

（ただし $C_{N}^{0}$ は純熔融鉄の窒素的和溶解度, $C_{N}^{M}$ は $\mathrm{Fe}-$ $\mathbf{N}-\mathbf{M}$ 系熔融合金の窒素飽和溶解度）

なる関係のあることは周知のとおりである.

前述の実験結果を上式によつて計算し $f_{N}^{(\mathrm{C})}, f_{N}^{(S 1)}$ お よび $f_{N}^{(M n)}$ を求め, それぞれの対数と炭素, 珪素および マンガン量との関係を求めると Fig. 6 に示すごとくで
ある・

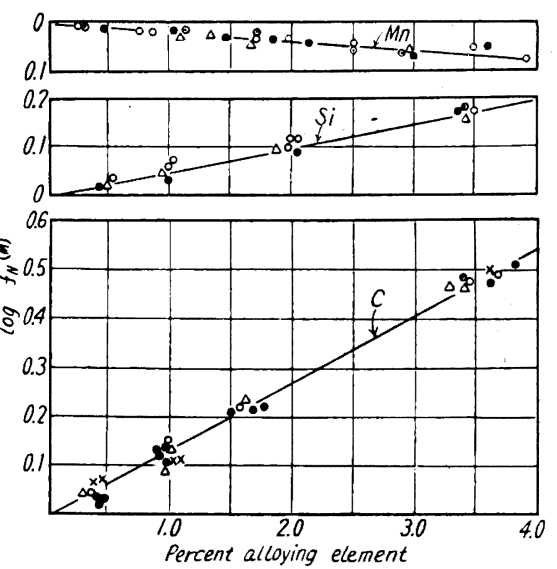

Fig. 6. Effect of alloying elements on the logarithms of activity coefficient of nitrogen.

すなわち, $\log f_{N}^{(\mathrm{C})}, \log f_{N}^{(\mathrm{S} 1)}$ および $\log f_{N}^{(\mathrm{Mn})}$ と炭素, 珪素およびマンガン量とは，それぞれ直線関係を示して いる.

よつてこれらの関係より

$$
\left.\begin{array}{ll}
\log f_{N}^{(\mathrm{C})}=+0.135 \cdot \% \mathrm{C} & 1500 \sim 1700^{\circ} \mathrm{C} \\
\log f_{N}^{(\mathrm{Si})}=+0.048 \cdot \% \mathrm{Si} \\
\log f_{N}^{(\mathrm{Mn})}=-0.020 \cdot \% \mathrm{Mn}
\end{array}\right\} \quad \begin{array}{ll}
1550 \sim 1700^{\circ} \mathrm{C} \\
\log
\end{array}
$$

が得られる。

2. 彷来の研究結果との比較

i ）窒素の溶解度

1）純熔鉄の窒素溶解度：前揭 Fig. 3 に純熔鉄の 窒素溶解度に関寸る既往研究結果の 2,3 汇ついて示し たが，窒素圧 $760 \mathrm{~mm}, 1600^{\circ} \mathrm{C}$ におけるおもな研究の

\begin{tabular}{|c|c|}
\hline $\mathrm{N}_{2}$ Pct. & Source \\
\hline $\begin{array}{l}0.032\left(1530^{\circ} \mathrm{C}\right) \\
0.038\left(1580^{\circ} \mathrm{C}\right) \\
0.039\end{array}$ & $\begin{array}{l}\left.\text { SIEVERT \& } Z_{\text {APF }^{7}}\right) \\
\text { BRICK \& (REEVY } \\
\text { SAITo, et al }{ }^{2} \text { ) }\end{array}$ \\
\hline $0 \cdot 040$ & $\begin{array}{l}\text { CHIPMAN \& MURPHY }{ }^{1} \text {, SANO } \\
\text { \& MINOWA } \\
\text { (E), This reserach }\end{array}$ \\
\hline $0 \cdot 0425$ & VASHYAP \& PARLEE \\
\hline $0 \cdot 044$ & $\begin{array}{l}\text { SaIto, et a12), MatoBA \& } \\
\text { KASAMATSU }\end{array}$ \\
\hline $0 \cdot 045$ & Schenck, Frohlberg \& Grof ${ }^{\theta}$ \\
\hline
\end{tabular}
純鉄の窒素溶解度を示すと Table 2 のごとくである.

Table 2. Solubility of nitrogen in iron at $1600^{\circ} \mathrm{C}$ $\left(\mathrm{P}_{N}=760 \mathrm{mmHg}\right)$

すなわち, 従来の研究は 0.032〜0.046\% の範囲に収 まつているが箻者らの結果は幾分低い方に属している. 
これは純鉄中の微量成分や，実験方法に影響されるもの と考党る.

これらの点については後報に多少触れるので, ここで は省略する・

口） $\mathrm{Fe}-\mathrm{C}, \mathrm{Fe}-\mathrm{Si}$ および $\mathrm{Fe}-\mathrm{Mn}$ 系熔融合金の窒素 溶解度: これらの系の既往研究結果と本研究結果との 比較を Fig. 7 に示した.

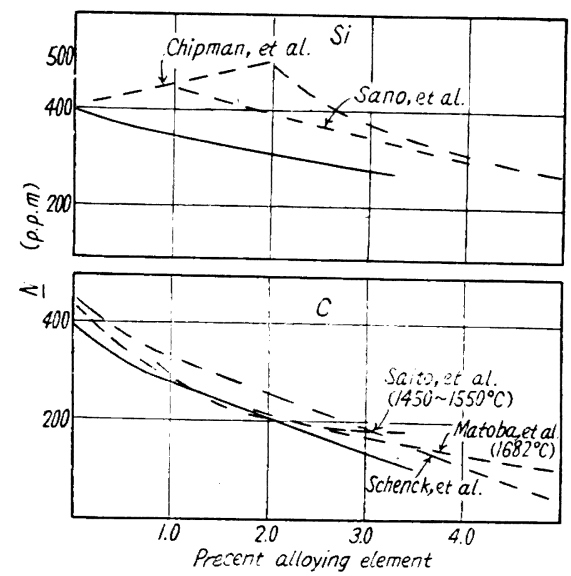

Fig. 7. Effect of carbon and silicon on the solubility of nitrogen in iron at $1600^{\circ} \mathrm{C}$.

ただし，マンガンの場合は，明確な結果を示している ものがなかつたので省略した。図に明らかなように炭素 の場合は，ほ办の研究結果と大体よく一致しているが， 珪素の場合は前述のごとくかなり異なつた結果を示して いる.これについては後報において詳しく検討する.

ii) 窒素の活量係数

1) $\mathrm{Fe}-\mathrm{C}$ 采: 本采については CHIPMAN ${ }^{10)}$ は $\log f_{N}^{(\mathrm{C})}=+0 \cdot 13 \cdot \%$ C $1600^{\circ} \mathrm{C}$

的場, 笠松11)

$\log f_{N}^{(\mathrm{C})}=+0 \cdot 147 \cdot \% \underline{\mathrm{C}} \quad 1566 \sim 1682^{\circ} \mathrm{C}$

SCHENCK $\left.{ }^{9}\right)$ は

$$
\log f_{N}^{(\mathrm{C})}=+0 \cdot 125 \cdot \% \underline{\mathrm{C}}
$$

斉藤 $\left.{ }^{12}\right)$ は

$$
\log f_{N}^{(\mathrm{C})}=+0.024 \cdot \% \mathrm{C} \quad 1450 \sim 1550^{\circ} \mathrm{C}
$$

をあたえているが，筆者らの值と，大体よく一致してい るものが多い。

ロ） $\mathrm{Fe}-\mathrm{Si}$ 系： 本采については $1600^{\circ} \mathrm{C}$ で $\mathrm{C}_{\text {HIP- }}$ MAN ${ }^{10)}$ は

$$
\log f_{N}^{(S i)}=-0.038 \cdot \% \underline{S i}
$$

佐野, 䘫輪12)は

$$
\log f_{N}^{(S 1)}=-0.030 \cdot \% \text { Si }
$$

をそれぞれ示して筆者らの結果と, 全く逆の結果を示し
ている.しかし，実験の精度より筆者らの結果が正しい ものと考えられる. この点については後報に詳述する.

八） Fe-Mn 采：本系については WENTRUP と $\operatorname{REIF}^{13}$ )

$$
\log f_{N}^{(\mathrm{Mn})}=-0.018 \cdot \% \mathrm{Mn}
$$$$
\log f_{N}^{(\mathrm{Mn})}=-0.024 \cdot \% \mathrm{Mn} \quad 1600 \sim 1700^{\circ} \mathrm{C}
$$

斉藤12)は

LANGENBERG $\left.{ }^{14}\right)$ は

$$
\log f_{N}^{(\mathrm{Mn})}=-0.025 \% \% \mathrm{Mn} \quad 1600^{\circ} \mathrm{C}
$$

をそれぞれ示していて筆者らの值とも大体よく一致し ている.

\section{V. 結言}

純 $\mathrm{Fe}, \mathrm{Fe}-\mathrm{C}, \mathrm{Fe}-\mathrm{Si}$ および $\mathrm{Fe}-\mathrm{Mn}$ 系熔融合金の 各種温度における窒素溶解度を求めたが,

純熔鉄の公素溶解度は

$\% \underline{N}=1 \cdot 2 \times 10^{-5} \cdot T+0 \cdot 0171$

で表わされる.

また，

$1 / 2 N_{2}=\underline{N}$

$\log K\left(=\% \mathrm{~N} / \sqrt{\overline{\left.P_{N}\right)}}=-500 / T-1 \cdot 136\right.$

$\Delta F^{\circ}=2288+5 \cdot 20 \cdot T$

なる関係が得られた。

本実娩の温度範囲こは，熔鉄中の窒素の活量におよほ す炭素, 珪素およびマガンンの影響に関しては, つぎの ごとき関係が得られた。

$$
\begin{aligned}
& \log f_{N}^{(\mathrm{C})}=0.135 \cdot \% \text { C } \quad \mathrm{C}<4 \% \\
& \log f_{N}^{(\mathrm{Si})}=0.048 \cdot \% \text { Si } \quad \mathrm{Si}<4 \% \\
& \log f_{N}^{(\mathrm{Mn})}=-0.020 . \% \mathrm{Mn} \quad \mathrm{Mn}<4 \%
\end{aligned}
$$

(昭和 35 年 4 月寄稿)

$$
\text { 文献 }
$$

1) J. Chipman \& D. W. Murphy: Trans. Met. Soc., Amer. Inst. Min., Met. \& Pet. Eng., 116 (1935), p. 179

2) 斎藤, 川合, 粟野: 東北大選研報, 5 (1949), p. 33-

3) 的場, 笠松: 学振資料, 19 委 4510 (1957)

4 ) V. C. Kashyap \& N. Parlee: Trans. Met. Soc., Amer. Inst. Min., Met. \& Pet. Eng., 212 (1958), p. 86

5 ) J. Chipman \& J. C. Vaughan: Trans. Met. Soc., Amer. Inst. Min., Met. \& Pet. Eng., 140 (1940), p. 224

6 ）佐野, 致輪: 日本金属学会誌, 21 (1957), p. 569

7) A. Sieverts \& G. Z APF: Z. Phys. Chem. A., 172 (1935), p. 314

8 ) R. M. Brick \& J. A.Greevi: Metals Tech. 7 (1940), No.3 
9), H. Schenck, M. G. Frohberg \& H. Graf: Arch. Eisenhüttenw., 29 (1958), p. 673

10) J. Chipman: J. Iron \& Steel Inst. (U.K.), 180 (1955), .p. 97

11）的場, 笠松: 学振資料 19 委 5107（1958)
12) 的場，不破：同上 19 委 5593 (1959) より転載

13) H. Wentrup \& O. Reif: Arch. Eisenhüttenw., 20 (1949), p. 359

14) F. C. Langenberg: J. Metals. Aug. (1956), p. 1099

\title{
連続鋳造における二次冷却についで*
}

（鋼の連続鋳造に関する研究一II）

\section{明田義男**.牛島清 人** \\ On the Secondary Cooling of Continuous Casting.}

\author{
(Study on continuous casting of steel-II) \\ Yoshio Aketa and Kiyoto Ushijima
}

\begin{abstract}
Synopsis:
A series of experiments on the secondary cooling of continuous casting of steel was carried out. As the authors defined in the first report, it was stated that the solidification in the spray zone was "the secondary solidification" and the cooling of this stage was "the secondary cooling "'.

Based on the principle of normal ingot casting, authors thought that main factors affecting the secondary solidification of continuous casting should be as follows:

Evenness of cooling in the spray zone

Intensity of the spray cooling

Casting temperature

Casting speed

Experiments on the relationship between these factors and their effects on continuous cast billet mainly of square type revealed the following facts:

(1) To prevent deformation and cracks of billets, it was necessary to set up roller aprons and to keep evenness of the spray cooling. (Photo. 1)

(2) Intensity of the spray cooling affected on inner cracks of billets. There was the limit intensity of spray cooling for each grade of steel to get rid of inner cracks of billets ( Table 2, 3 and Photo. 2).

(3). Too high casting temperature induced inner cracks of billets (Table 5 and Photo. 3). These relationships in continuous casting were just the same as those in normal ingot casting. Although not confirmed experimentally, the limit intensity of the spray cooling should be varied with casting speed.
\end{abstract}

\section{I. 緒言}

前報1において, 鋼の連続鋳造における溶鋼の凝固過 程を, 鋳型内における鋳片外層部の凝固と, これに続く 水のスプレー帯における鋳片内部の凝固とに分け, 前者 を一次凝固, 後者を二次凝固に呼び, それぞれの凝固を 支配する冷却過程をおのおの一次冷却ならびに二次冷却 と呼ぶことにした. そして, 一次冷却の諸因子が一次凝 固すなわち鋳片外層部の性状におよほす影響について述 ベた. 本報においては上記のごとく定義した二次冷却が
鋳片の性状におよほす諸種の影響について述べる。

さて二次冷却は, 鋳片内部の凝固の進行すなわち二次 凝固を支配するばかりでなく，すでに凝固の完了した鋳 片外層部すなわち一次凝固部の冷却をも支配する. 高温 でしかも内部がなお溶融状態にある鋼の外層表面に水の スプレーを施す, この連続鋳造独特の冷却過程は, 普通 造塊法における冷却過程とは全く趣を異にするものであ

* 昭和 34 年 11 月本会講演大会にて発表

** 住友金属工業株式会社車輛鍀鈠事業部 